\title{
The Role of Gender and Immersion in Communication and Second Language Orientations
}

\author{
Susan C. Baker and Peter D. MacIntyre \\ University College of Cape Breton
}

\begin{abstract}
The present study examines the nonlinguistic outcomes of an immersion versus a nonimmersion program. The dependent variables included attitudes toward learning French, orientations for learning, willingness to communicate, communication anxiety, perceived communicative competence, and self-reported frequency of communication in both English (L1) and French (L2). Immersion students indicated higher willingness to communicate, lower communication anxiety, higher perceived communicative competence, and more frequent communication only in the French language. Among the nonimmersion students, perceived competence was strongly correlated with willingness to communicate, but among the immersion students, communication anxiety correlated most strongly with willingness to communicate. Male nonimmersion students showed the least positive attitudes toward learning
\end{abstract}

Susan C. Baker, Peter D. MacIntyre, Department of Behavioral and Life Sciences.

This research was facilitated by a grant from the Social Sciences and $\mathrm{Hu}-$ manities Research Council of Canada with a grant to the second author. We would like to thank the teachers, staff, and students of Riverview High School and Sydney Academy, both in Sydney, Nova Scotia, for participating in this study and the assistance of Brenna Fraser in collecting the data. We are grateful for the advice of Katherine Covell in planning this research, which was conducted as part of the first author's undergraduate honors thesis.

Correspondence concerning this article may be sent to Peter MacIntyre, University College of Cape Breton, Sydney, NS, Canada B1P 6L2. Internet: pmacinty@uccb.ns.ca. 
French; female nonimmersion students showed higher endorsement of three of the four language learning orientations.

Despite the truism that communication in an L2 requires second language learning, research into communication and language learning has developed separately. When it comes to communication research, most of the attention has been given to the study of the native language. It would seem that combining communication and second language learning research would provide insights into individual differences in second language acquisition. Knowing what makes one individual a more proficient communicator than another in the second language may be instrumental in developing environments that promote second language learning. Indeed, the L2 context appears to have an important effect on such communication variables as willingness to communicate, perceived competence, and frequency of communication. MacIntyre and Charos (1996) found that when it came to context, "having more opportunities for interaction in French may lead to an increase in perceived competence, a greater willingness to communicate in French, and more frequent communication" (p. 17).

The notion of an opportunity for interaction leads to the distinction between second language and foreign language learning environments. A second language is "one that is learned in a location where that language is typically used as the main vehicle of everyday communication for most people" (Oxford \& Shearin, 1994, p. 14). On one hand, the second language context provides constant visual and auditory stimulation in the target language. On the other hand, a foreign language is "one that is learned in a place where that language is not typically used as the medium of ordinary communication" (Oxford \& Shearin, 1994, p. 14). Foreign language learners are at a disadvantage because they are surrounded by their own native language and must search for stimulation in the target language. The foreign language student typically receives input from the target language only in a classroom setting 
and lacks the opportunities that a second language learner would have to practice the target language on a daily basis. Extrapolating the findings of MacIntyre and Charos (1996), if foreign language learners lack the opportunity for constant interaction in the L2, they should be less likely to increase their perceived competence, willingness to communicate, and frequency of communication.

Parallel to the distinction between second and foreign language learning environments is the distinction between immersion and nonimmersion learning programs. Like students in a second language learning environment, immersion students, compared to nonimmersion students, have more contact with the target language and the kind of stimulation necessary to better master communication in the target language. Gardner (1996) discussed two sets of possible outcomes that result from language learning situations: linguistic and nonlinguistic. Linguistic outcomes are those skills that involve language material. Nonlinguistic outcomes involve such things as satisfaction with the experience, attitudes, motivation, and anxiety (Gardner, 1996, p. 34). Immersion programs offer increased frequency of communication in the second language and, thus, enhance the linguistic outcomes of immersion students. However, the effects of immersion on the nonlinguistic aspects of second language learning, like anxiety and a willingness to communicate, require exploration. Immersion students may possess the necessary skills to communicate in the second language, but do they perceive greater L2 competence, are they more or less anxious, and are they more willing to communicate than nonimmersion students? How does immersion in the L2 affect these variables in the L1? Also, what are the differences with respect to attitudes and reasons for L2 learning? Finally, are there gender differences between immersion and nonimmersion students on these types of variables? These questions will be the focus of the present study.

Clearly, talking is a major part of interpersonal communication, but there is substantial variability among individuals in how much they talk, even in the L1. This variability is expressed in a 
personality-based predisposition which McCroskey and Baer (1985) labelled "willingness to communicate" (WTC). They argued that cognitions about communication are strongly affected by one's personality. Specifically, a person makes a cognitively processed, volitional choice whether or not to communicate. The personality of the individual, then, will play a major role in the kind of choice that is made. McCroskey and Richmond (1991) did not ignore the notion that willingness to communicate can be dependent on the situation, but they asserted that research has found that people do possess regular willingness to communicate across a variety of situations (also refer to Borgatta \& Bales, 1953; Chapple \& Arensberg, 1940; Goldman-Eisler, 1951). The WTC construct has evolved from the work of Burgoon (1976), who developed the concept of unwillingness to communicate, Mortensen, Armstrong, and Lustig (1977), who discussed predispositions toward verbal behavior, and McCroskey and Richmond (1982), who took a behavioral approach to shyness. The assumption that willingness to communicate is traitlike means that a person's WTC in one situation can be expected to correlate with his/her WTC in other situations and with different receivers. The results of the research on the WTC scale (McCroskey, 1992), which is based on four communication contexts and three types of receivers, is encouraging. McCroskey and Richmond (1987) found support for their notion of a general predisposition of a willingness to communicate. The question, then, is from where does this predisposition originate? Two variables that appear to be key are anxiety and perceived competence (see MacIntyre \& Clément, 1996).

Communication apprehension has been defined as "an individual's level of fear or anxiety associated with either real or anticipated communication with another person or persons" (McCroskey, 1970, 1977, 1984). McCroskey and Richmond (1991) argued that communication apprehension is the single best predictor of an individual's willingness to communicate. In their research, McCroskey and McCroskey (1986) found a significant negative correlation between communication apprehension and 
willingness to communicate. Simply put, the greater the anxiety, the less likely the person will be willing to communicate. There is a strong belief that communication apprehension is learned and is based on expectancies for success in communicating. When expectations are consistently confirmed, a person develops confidence. If, however, expectations are repeatedly inaccurate and there is a need to produce new expectations each time, apprehension will result (McCroskey \& Richmond, 1987). According to McCroskey and Richmond (1987), "Formal instruction in communication adds to our cognitive capacity to develop such expectations and choose appropriate behaviors. To the extent that our behaviors continue to be reinforced, stronger positive expectations are developed and our communication behavior becomes more regularly predictable" (p. 147). Thus, it is possible that immersion students, compared to nonimmersion students, will show lower levels of communication apprehension because of formal instruction and greater experience in L2 communication.

The other major variable found to predict willingness to communicate is perceived competence. Communication competence can be defined as "the individual's ability to properly process information in such a way that communicative behaviors occur in some orderly, rule-governed way" (Sellers \& Stacks, 1990, p. 46). It is believed that a lack of communication skills plays a major role in lowering one's willingness to communicate. This suggestion comes from the work on reticence, which is identified as a reluctance to speak. In the early work, reticence was considered a function of anxiety about communicating. Phillips (1968, p. 40) initially defined a reticent individual as "a person for whom anxiety about participation in oral communication outweighs his projection of gain from the situation." However, more recent work has focussed on communication skills. Phillips (1968) and other researchers did not deny that many people feel anxious about communicating in a variety of situations, but they suggested that the explanation for anxiety is a lack of communication skills. Phillips $(1968,1977)$ found that reticent persons increased their willingness to speak in a particular area when their skills in that area increased. This 
confirms the notion that when people lack the appropriate communication skills, they are less willing to communicate (MacIntyre, 1994, in L1; MacIntyre \& Charos, 1996, in L2).

Assessing communication competence is a complex task rendered more difficult by different perceptions of what competence really means. It may be that one individual feels completely competent, even though he is not, whereas another with higher skill chooses to maintain her silence. We would argue then that it is not the individual's actual skill that counts; rather it is how they perceive their communication competence that will determine WTC (see also McCroskey \& Richmond, 1990). The research of McCroskey and McCroskey (1986) found a strong correlation between perceived competence and willingness to communicate (see also MacIntyre, Babin, \& Clément, 1999). "Since the choice of whether to communicate is a cognitive one, it is likely to be more influenced by one's perceptions of competence (of which one usually is aware) than one's actual competence (of which one may be totally unaware)" (McCroskey \& Richmond, 1991, p. 27).

There seems to be a close relation between anxiety and perceived competence. Clément (1980) noted that anxiety was consistently associated with perceived competence in a second language (see also Gardner, Smythe, Clément, \& Gliksman, 1976; Gardner, Smythe, \& Lalonde, 1984). MacIntyre, Noels, and Clément (1997) found that anxiety can bias perceptions of competence, where anxious speakers underestimate and relaxed speakers overestimate their own level of competence. This suggests that the relation between anxiety and perceived competence evolves over time. At early stages of language learning, students might experience a vicious cycle. Those with higher anxiety and lower perceived competence likely will be less willing to communicate and thus avoid L2 communication. When people avoid these behaviors, they deprive themselves of the opportunity to improve their proficiency and experience. Without an improvement in proficiency, it is unlikely that the person will experience a reduction in anxiety or an increase in perceived competence. Indeed, willingness to communicate and perceived competence have been 
shown to have an impact on frequency of communication. Positive experiences communicating in the second language not only reduce anxiety, improve perceived competence, and enhance willingness to communicate, but also can increase the motivation to participate in similar experiences in the future (in Hines \& Barraclough, 1995).

In comparing second and foreign language learning environments, Oxford and Shearin (1994) focussed on the concept of motivation and whether or not motivation differs from a second to a foreign language environment. "Motivation has been widely accepted by both teachers and researchers as one of the key factors that influence the rate and success of second/foreign language (L2) learning" (Dörnyei, 1998, p. 117). Motivation is the driving force that initiates learning in the first place and sustains learning when the situation becomes difficult. Motivation can even compensate for a deficiency in aptitude. Gardner and Lambert (1972) found that, although aptitude accounts for a great deal of the variability among individuals, motivation can actually override the effects of aptitude. They argued that regardless of aptitude, people still manage to learn a second language.

In conjunction with research on motivation, there has been much research concerning the reasons for learning another language. Gardner and Lambert (1959) have referred to these reasons as "orientations" but they should not be confused with the broader concept of motivation (Gardner, 1996). Gardner (1985) asserted that motivation has three characteristics-desire to achieve a goal, effort expended toward the goal, and pleasure associated with the task. Thus goals, or orientations, are important components of motivation.

Gardner (1985) defined motivation to learn a second language as "the extent to which an individual works or strives to learn the language because of a desire to do so and the satisfaction experienced in this activity" (Gardner, 1985, p. 10). Gardner's construct of motivation has three components: motivational intensity, desire to learn the language, and an attitude toward the act of learning the language. According to Gardner, a truly motivated 
individual shows all three components. The underpinnings of motivation to learn a second language are somewhat different from the motivation to master other subjects. Mastery of a second language involves, to some degree, taking on the identity and culture of the target language. Gardner's theory takes the position that students' attitudes toward the target language group will affect their success in learning that language. The relationship between positive attitudes and L 2 motivation can be influenced significantly by the amount of contact between the two cultures. "Indeed, variables such as a preference for, knowledge of, and self-confidence in L2 use have been shown to be linked to lower levels of stress, to a greater sense of personal control, and higher levels of satisfaction with the self as well as with society in a variety of ethnic groups" (MacIntyre, Clément, Dörnyei, \& Noels, 1998, p. 556).

Gardner's (1985) model also makes a distinction between integrative and instrumental motivation. Integrativeness is described as a positive temperament toward the target language group and the desire to interact with members of that community. Instrumentality is related to the pragmatic gains of learning the target language. Dörnyei (1990) argued that, with regard to foreign language learners, integrative motivation might be less relevant than for those in a second language environment (Oxford \& Shearin, 1994). Foreign language learners have very little contact with the target language group so they may feel less need to integrate with that group. Therefore, it follows that immersion students might be more integratively motivated than nonimmersion students because they are more committed to integrate within the target language group in order to attain an optimal level of L2 proficiency. The effect of immersion on instrumental orientation is more difficult to predict. However, while instrumental motivation may be more relevant for nonimmersion students, Dörnyei (1990) argued that integrative motivation is often necessary to achieve a certain level of proficiency in the L2. In addition to instrumental orientation, Clément and Kruidenier (1983) found three other orientations-knowledge, friendship, and travel一that 
were common across majority and minority language groups. These three orientations could be considered variants of integrative orientation, but they could also be treated as distinct orientations. The present study will treat these four orientations as distinct.

A final issue to be examined in this study is potential gender differences in immersion and nonimmersion programs. This issue has not been addressed widely in the literature. Previously it was accepted that, in general, gender differences showed enhanced performance of women on verbal tasks and men on spatial tasks (Maccoby \& Jacklin, 1979; Tittle, 1986). This might lead to the hypothesis that the more intensive communication demands in an immersion program would be favored by females and could be associated with more positive reactions to L2 communication, greater motivation for language learning, and stronger orientations toward language learning among female students. The general literature on gender differences in educational settings has been widely criticized and such predictions should best be considered tenuous (Bowd, McDougall, \& Yewchuk, 1994).

The purpose of our research is to examine the differences in nonlinguistic outcomes between immersion and nonimmersion language students studying French. Specifically, the study examines how the two groups differ in their willingness to communicate, perceived competence, frequency of communication, and communication apprehension in L1 and L2. The present study was conducted in a rather unique linguistic context. Although Canada is a bilingual country, both the immersion and nonimmersion programs in this study were offered by schools that were located in a predominantly anglophone community. Here we have a small group of immersion students studying French among an ethnolinguistically dominant English-speaking population. Thus, the social situation might be somewhat closer to a foreign language than a second language environment.

It is expected that immersion and nonimmersion students will have similar levels of willingness to communicate, perceived competence, frequency of communication, and communication 
apprehension in English. In French, however, the immersion group should have higher willingness to communicate, perceived competence, and frequency of communication, and lower communication apprehension. Finally, gender differences in attitudes toward French and language learning orientations will be examined.

\section{Method}

\section{Participants}

The participants included 71 immersion students (31 males, 39 females, and 1 student who did not indicate his/her sex) and 124 nonimmersion students ( 54 males, 70 females) from Grades 10,11 , and 12 . Of the 195 participants, $0.5 \%$ were 14 years of age, $28.9 \%$ were $15,26.3 \%$ were $16,34 \%$ were $17,9.8 \%$ were 18 , and $0.5 \%$ did not indicate their age. All participants had English as their L1 and were studying French (L2).

\section{Materials}

Communication variables were measured by presenting 12 communication contexts involving speaking to friends, acquaintances, and strangers in four settings: dyads, small groups, formal meetings, and public-speaking situations.

1. Perceived competence in French $(\alpha=.91)$ and English $(\alpha=.94)$. Twelve items from McCroskey, Richmond, and McCroskey (1987) assessed the average percentage of time that students felt competent using French and English to speak in 12 situations, for example, "talk in a small group of friends."

2. Willingness to communicate in French $(\alpha=.97)$ and English $(\alpha=.93)$. Twenty items from McCroskey and Baer (1985) assessed the average percentage of time that students would choose to communicate in French and English in a variety of 
situations, for example, "talk in a large meeting of friends." In addition to the 12 speaking contexts noted in Number 1 above, 8 "filler" items were also included in the score, for example, "talk with a secretary."

3. Frequency of communication in French $(\alpha=.93)$ and En-glish $(\alpha=.91)$. Items from the perceived competence scale were adapted to measure the frequency of communicating in French and English for each of the 12 situations, using a 7-point scale with the anchors never and many, many times. A potential range of scores was 0 to 72. An example is "talk with an acquaintance."

4. Communication anxiety in French $(\alpha=.95)$ and English $(\alpha=.92)$. Twelve items from McCroskey, Richmond, and McCroskey (1987) assessed the average percentage of nervousness that students felt in communicating in French and English in 12 situations, for example, "when presenting a talk to a group of strangers."

5. Reasons for studying French (Clément \& Kruidenier, 1983). Sixteen items measured students' reasons for studying French in four areas: getting a good job (4 items, $\alpha=.78$ ), travelling (4 items, $\alpha=.82$ ), meeting Francophones ( 4 items, $\alpha=.87$ ), and personal achievement ( 4 items, $\alpha=.72$ ). Students rated how much they agree or disagree with each statement from 1 (strongly agree) to 6 (strongly disagree). An example is "it will be useful in getting a good job."

6. Attitude/motivation index (Guilford version of Gardner's Attitude/Motivation Test Battery [AMTB]; see Gardner \& MacIntyre, 1993). Eleven items assessed students' attitudes and motivation toward French and French Canadians ( $\alpha=$ .72). Items were measured on a 7-point scale. The 2 anxiety items were recoded to represent a lack of anxiety before being combined with the other items. A high score indicates more favorable attitudes and higher motivation. The 11 items represented attitudes toward French Canadians, interest in foreign languages, integrative orientation, French course 
evaluation, French teacher evaluation, motivational intensity, desire to learn French, attitude toward learning French, French class anxiety, French use anxiety, and instrumental orientation. An example is "my desire to learn French is" with the anchors weak to strong.

\section{Procedure}

The students were tested during their regular class time in their classrooms. Data were collected using a questionnaire in which students were asked to respond to questions pertaining to their willingness to communicate, perceived competence, frequency of communication, and communication apprehension in both French- and English-language situations. Students' attitudes toward various French-language situations were also assessed. They were also asked to write about either a positive or a negative experience about speaking French. The kind of experience described, positive or negative, was assigned by the researchers. The questionnaires were randomly mixed so that, of the 174 who responded, 85 students wrote about a positive experience and 89 wrote about a negative experience. Finally, students were asked about their motivation to learn French.

\section{Results}

The objectives of the study were to (a) determine the correlations among the communication variables in immersion and nonimmersion students; (b) assess the effects of gender and the immersion program on willingness to communicate, perceived competence, frequency of communication, and communication anxiety in English and French; (c) measure the effects of gender and program on attitudes toward French and reasons for studying French; and (d) examine qualitatively the nature of the positive and negative experiences described by the students. 
Correlations Among the Communication Variables

The intercorrelations among the communication variables for the immersion students are presented in Table 1. Generally, the expected correlations were obtained. Willingness to communicate in French was significantly correlated with anxiety in French, frequency of communication in French, and willingness to communicate in English. An interesting finding was that perceived competence in French was not significantly correlated with willingness to communicate in French among immersion students.

The intercorrelations among the communication variables for the nonimmersion students are also presented in Table 1. Generally, the expected correlations were obtained. Willingness to communicate in French was significantly correlated with anxiety in French, frequency of communication in French, perceived competence in French, and willingness to communicate in English. The correlation between willingness to communicate in French and perceived competence in French, which was nonsignificant in the immersion group, was quite strong for the nonimmersion students.

\section{Effects of Immersion on Communication Variables}

A $2 \times 2 \times 2$ split plot multivariate analysis of variance (MANOVA) was performed using the between-subjects factor of gender (male/female) and program (immersion/nonimmersion) and the within-subjects factor of language (English/French). The four dependent variables were communication apprehension, frequency of communication, willingness to communicate, and perceived competence. Communication apprehension was recoded to represent a lack of communication apprehension in order to maintain positive correlations among the dependent variables in the analysis. Results of the analysis are presented in Table 2 . The MANOVA revealed a significant main effect of language (lambda $=.546$ ), a significant main effect of program, and a significant language-by-program interaction (lambda $=.890$ ). None of the effects involving gender were significant. Significant multivariate 


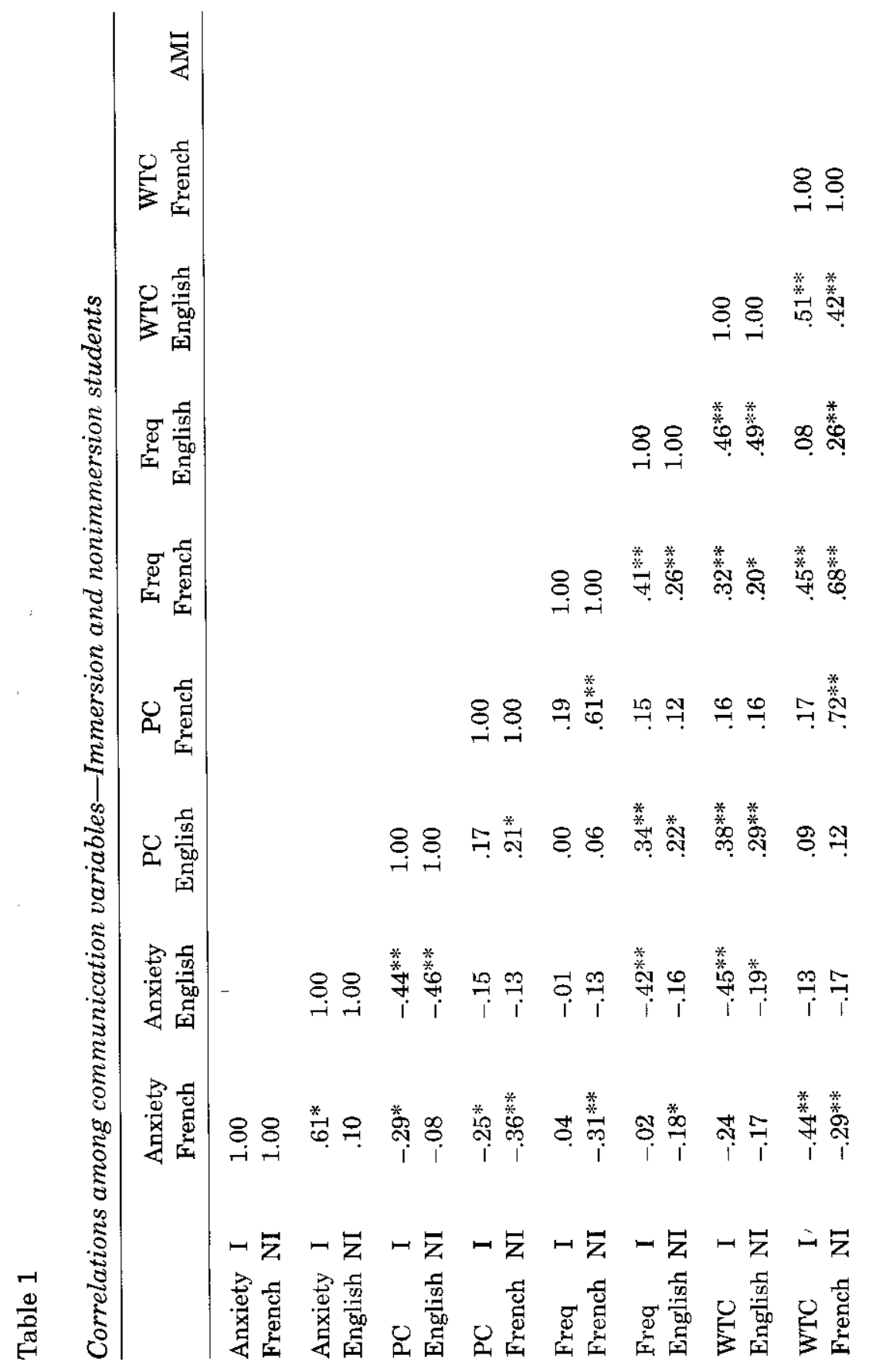




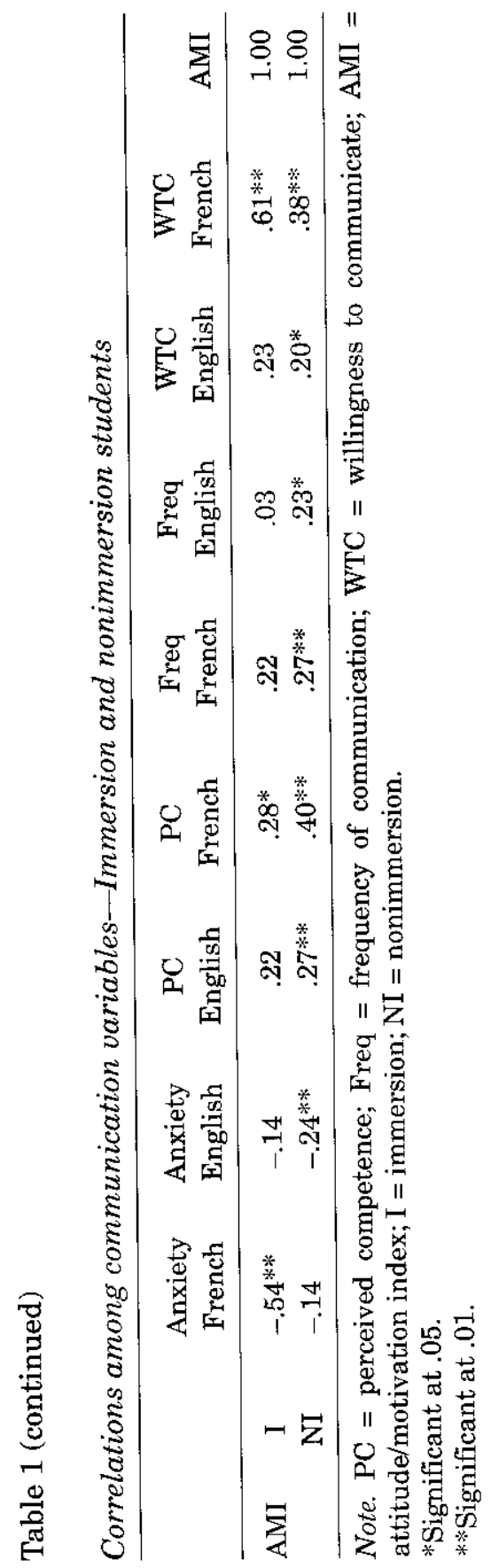


effects were followed up at the univariate level. For all four dependent variables, a significant main effect of language, a significant main effect of program, and a significant program-by-language interaction were obtained.

Post hoc analysis of means using orthogonal contrasts was performed to test for differences between the means of immersion and nonimmersion students. In all four communication variables, there was no significant difference between the means of the

Table 2

Partial MANOVA summary table: Effects of program and language on communication

\begin{tabular}{lrcc}
\hline & $F$ & $d f$ & Eta squared \\
\hline Main effect of language & & & \\
MANOVA & $155.423^{*}$ & 1,187 & .454 \\
Univariate & & & \\
$\quad$ WTC & $253.064^{*}$ & 1,192 & .569 \\
PC & $15.425^{*}$ & 1,192 & .074 \\
Freq & $365.979^{*}$ & 1,192 & .656 \\
CA & $87.210^{*}$ & 1,192 & .316 \\
Main effect of program & & & \\
MANOVA & $14.851^{*}$ & 1,187 & .074 \\
Univariate & & & \\
WTC & $7.859^{*}$ & 1,192 & .039 \\
PC & $10.407^{*}$ & 1,192 & .051 \\
Freq & $20.858^{*}$ & 1,192 & .098 \\
CA & $7.854^{*}$ & 1,192 & .040 \\
Language by program & & & \\
MANOVA & & 1,187 & .110 \\
Univariate & $23.003^{*}$ & & \\
WTC & & 1,192 & .063 \\
PC & $12.914^{*}$ & 1,192 & .064 \\
Freq & $13.191^{*}$ & 1,192 & .113 \\
CA & $24.492^{*}$ & 1,192 & .028 \\
\hline Note. WTC & $5.392^{*}$ & & \\
\hline
\end{tabular}

Note. WTC $=$ willingness to communicate $\mathrm{PC}=$ perceived competence; Freq = frequency of communication; $\mathrm{CA}=$ lack of communication apprehension. * Significant at .05 . 
communication variables in English (L1), but there were significant differences between the two groups in French (L2). The means and standard deviations for the four variables are provided in Table 3. Compared to nonimmersion students, the immersion students showed lower communication apprehension, higher willingness to communicate, greater perceived competence, and more frequent communication in French (see Figure 1). For presentation, the means for this analysis shown in Figure 1 have been placed on a common scale, ranging from 1 to 100 , by taking a percentage of the maximum score and multiplying by 100 .

\section{Table 3}

Effects of program and language on communication: Summary of means

\begin{tabular}{lrlrr}
\hline & Language & \multicolumn{1}{c}{ Program } & \multicolumn{1}{c}{$M$} & $S D$ \\
\hline WTC & \multirow{2}{*}{ English } & Immersion & $1,413.15$ & 345.42 \\
& & Nonimmersion & $1,385.56$ & 348.16 \\
& \multirow{4}{*}{ French } & Immersion & 962.77 & 525.87 \\
& & Nonimmersion & 672.49 & 544.30 \\
PC & English & Immersion & 988.03 & 232.54 \\
& & Nonimmersion & 994.49 & 182.16 \\
& \multirow{2}{*}{ French } & Immersion & 971.96 & $1,134.21$ \\
& & Nonimmersion & 583.51 & 336.30 \\
& \multirow{2}{*}{ English } & Immersion & 56.46 & 12.39 \\
& & Nonimmersion & 54.81 & 14.04 \\
& \multirow{3}{*}{ French } & Immersion & 37.69 & 12.98 \\
& & Nonimmersion & 22.93 & 17.99 \\
& \multirow{2}{*}{ English } & Immersion & 990.09 & 166.48 \\
& & Nonimmersion & 961.85 & 214.86 \\
& \multirow{2}{*}{ French } & Immersion & 815.39 & 262.44 \\
& & Nonimmersion & 671.52 & 338.70 \\
\hline
\end{tabular}

Note. $\mathrm{WTC}=$ willingness to communicate; $\mathrm{PC}=$ perceived competence; Freq $=$ frequency of communication; $\mathrm{CA}=$ lack of communication anxiety. 


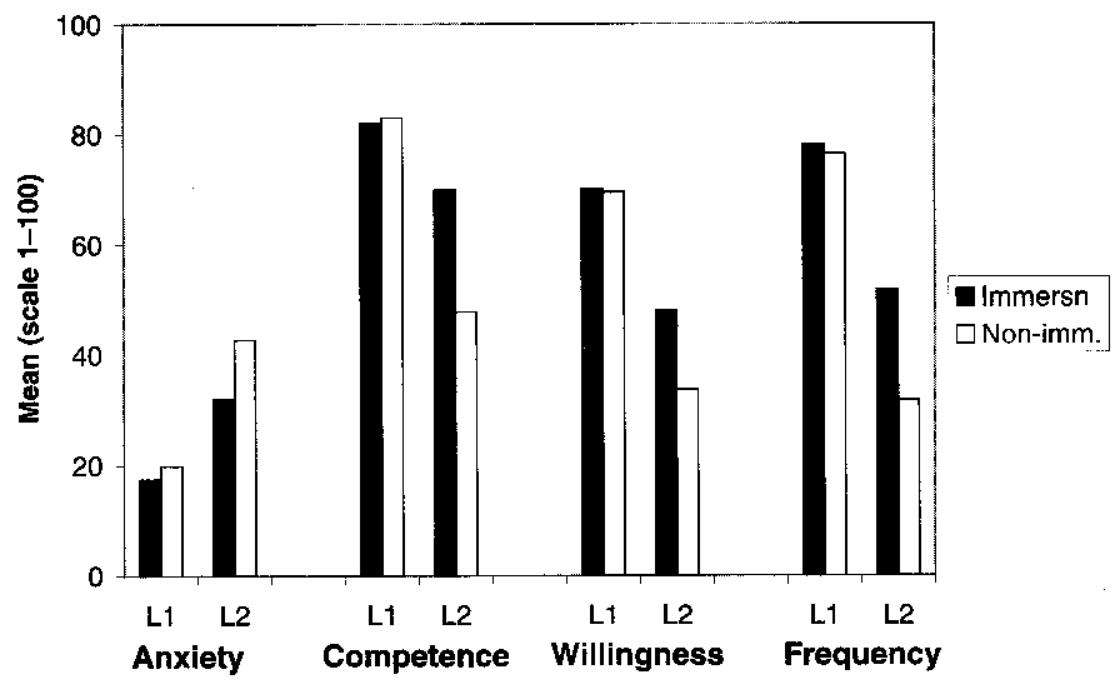

Figure 1. Mean scores for communication variables by language and immersion program.

Effects of Program on Attitudes / Motivation and Reasons for Studying French

To assess differences in attitudes and motivation for learning French, the attitude/motivation index was entered as the dependent variable in a $2 \times 2$ ANOVA, with the factors gender and program. The main effects for both gender, $F(1,190)=2.57$, and program, $F(1,190)=.93$, were not significant. However, a significant interaction for gender-by-program was observed, $F(1,190)=$ $5.10, p<.05$. Inspection of the means indicates that among the immersion students, males $(M=56.6)$ and females $(M=55.6$ ) showed similar attitude/motivation index (AMI) scores, $Q(2,190)$ $=0.57, n s$. Among the nonimmersion students, females $(M=57.6)$ showed a significantly higher AMI, $Q(2,190)=4.51, p<.05$, than did males $(M=51.6)$. 
To investigate the effects of gender and program on the four orientations for language learning, a $2 \times 2$ MANOVA was conducted. Results of the MANOVA are presented in Table 4. At the multivariate level, there was a significant main effect for program (lambda $=.924)$ and a marginally significant effect for gender (lambda $=.951$ ), both of which were tempered by a significant gender-by-program interaction (lambda $=.930$ ).

Table 4

MANOVA summary table: Effects of program and gender on orientations

$F \quad d f \quad$ Eta squared

Main effect of program

MANOVA

$3.85^{*}$

4,187

.076

Univariate

Job

$9.621^{*}$

1,190

.048

Travel

.633

1,190

.003

Meeting

1.134

1,190

.006

Personal

.109

1,190

.001

Main effect of gender

MANOVA

$2.39 *$

4,187

.049

Univariate

Job

Travel

Meeting

Personal

$\begin{array}{ccc}.004 & 1,190 & .000 \\ 4.542^{*} & 1,190 & .023 \\ .746 & 1,190 & .004 \\ 4.417^{*} & 1,190 & .023\end{array}$

Program by gender

MANOVA

$3.52^{*}$

4,187

.070

Univariate

Job

Travel

Meeting

Personal
$7.229^{*}$

1.544

$5.944 *$

$7.238 *$
1,190

1,190

1,190

1,190
.037

.008

.030

.037

Note. Job $=$ orientation for job; Travel $=$ orientation for travel; Meeting $=$ orientation for meeting Francophones; Personal = orientation for personal achievement.

*Significant at .05 . 
Inspection of the univariate results reveals a significant interaction on three of the four orientations: job related, meeting Francophones, and personal knowledge. Table 5 represents the mean orientation scores for the gender-by-program interaction. The $F$ test for the fourth orientation, travel, indicated a significant effect for gender at the univariate level, with males $(M=14.45)$ showing a significantly lower mean orientation than females ( $M$ $=15.87), Q(2,190)=3.58, p<.05$.

Qualitative Results

Nonimmersion, positive experience. Among the nonimmersion students, both male and female, the most frequently cited positive experiences speaking French concerned meeting new

Table 5

Mean orientation for gender-by-program interaction

\begin{tabular}{llccccc}
\hline & & \multicolumn{2}{c}{ Male } & \multicolumn{3}{c}{ Female } \\
Orientation & \multicolumn{1}{c}{ Program } & $M$ & $(S E)$ & $M$ & $(S E)$ & $Q$ \\
\hline \multirow{2}{*}{ Job } & & & & & & \\
& Immersion & 18.54 & $(.693)$ & 17.02 & $(.618)$ & 2.32 \\
\multirow{2}{*}{ Travel } & Nonimmersion & 15.18 & $(.525)$ & 16.78 & $(.461)$ & $3.24^{*}$ \\
& & & & & & \\
\multirow{2}{*}{ Meeting } & Immersion & 15.13 & $(.791)$ & 15.71 & $(.705)$ & 0.90 \\
& Nonimmersion & 13.78 & $(.599)$ & 16.01 & $(.526)$ & $4.53^{*}$ \\
& Immersion & 13.55 & $(.862)$ & 12.41 & $(.769)$ & 1.73 \\
Personal & Nonimmersion & 12.56 & $(.653)$ & 14.94 & $(.574)$ & $4.83^{*}$ \\
& & & & & & \\
& Immersion & 13.26 & $(.731)$ & 12.90 & $(.461)$ & 0.55 \\
& Nonimmersion & 11.41 & $(.554)$ & 14.34 & $(.486)$ & $5.94^{*}$ \\
\hline
\end{tabular}

Note. Job $=$ orientation for job; Travel $=$ orientation for travel; Meeting = orientation for meeting Francophones; Personal = orientation for personal achievement.

aThe gender-by-program interaction was not significant for the travel orientation, but the means are presented here for completeness.

${ }^{*} p<.05$. 
friends, travelling, and giving class presentations. When the nonimmersion students were asked to describe how the experience made them feel, $\mathbf{5 1 \%}$ used the words "wonderful," "happy," "satisfied," and "elated" after the experience. The positive experiences the students described were quite similar and only a few students recalled a specific event. For example, one female student said, "My father has a tailoring and bridal shop in Dartmouth and one day a Frenchspeaking lady came in and my dad's wife can speak French but she was off that day, so I was able to help her [the lady] out enough so that she would come back." A male student recalled travelling with his cadet troupe: "I am in Air Cadets and travel to various training centers through Canada each summer and meet French cadets."

Nonimmersion, negative experience. The most frequently described negative experience for the nonimmersion students involved speaking French to a Francophone and getting a reply in English. Among the nonimmersion students, 39\% said they felt "unsure," "self-conscious," "nervous," or "uncomfortable," and 34\% reported feeling "inadequate," "stupid," "unprepared," "incapable," or "inferior." It is interesting that these students were much more specific and detailed when they recalled a negative experience. One female student wrote, "I have been in a core French program throughout my education until this year. I have been integrated among many immersion students and even a few Francophones. Such an integration has affected me causing me to second-guess my abilities and causes me to become very nervous when in class. ..." A male student recalled an event while travelling in Europe: "One of the negative experiences was when I was in France. We went to a restaurant looking for vegetarian food. When I tried to explain to the chef what I wanted he did not understand, so we had to leave." This student went on to say that he was angrier with the chef than with himself.

Immersion, positive experience. The immersion students indicated that they felt most calm when speaking French to a close friend. They showed more indifference to the positive experience than did the nonimmersion students. Among the immersion students, 58\% used the terms "nice," "better," "good," "dandy," "fine," 
or "okay" to describe their feelings. The most common positive experience among the female students concerned giving presentations in class. Among the males, it was speaking to Francophones, for example, waiters and waitresses in restaurants or store clerks. The positive experiences referred to by males more often involved "out of school" situations. For example, one male said he felt confident "anytime that I spoke French that I didn't have to do so for a good mark. When I am marked I get a little nervous and start to mess up."

Immersion, negative experience. The negative experiences elicited stronger emotion from the immersion group. Among the immersion students, $62 \%$ said they felt "frantic," "anxious," "worried," and "incompetent," and 31\% felt "angry [with Francophones]," "mad," or "frustrated." As with the nonimmersion group, the most frequent negative experience concerned speaking to a Francophone in French and getting a reply in English. The males referred to "in class" situations, like class projects, when they recalled a negative experience. The females recalled situations where they feared being embarrassed by Francophones or where they felt their French was not good enough to carry on a conversation. One young lady wrote, "I was on a train coming back from Montreal and while I was sitting in the smoking car, an older woman struck up a conversation with me. Of course, she was Francophone and everybody around me could hear what we were saying. I felt like everyone was laughing at my ability to speak French compared to Francophones."

Whereas some of the students described intense feelings after a negative experience, overall only three of the students said they felt discouraged by the experience they described. Indeed, the majority of the students wrote that the negative situation was a learning experience, which indicated to them that they needed to improve their skills. Rather than feeling nervous, some of the students reported feeling even more determined to learn French. 


\section{Discussion}

In the nonlinguistic areas of language learning, clear differences exist between students from an immersion program and students from a nonimmersion program when it comes to selfreported communication. Both groups showed virtually equal willingness to communicate, perceived competence, communication anxiety, and frequency of communication in the English-language (L1) situations. The effects of the immersion program, however, were strongest for those same communication variables in the French-language (L2) situations. The increased contact with the language in the immersion program seems to give the students an opportunity to improve their ability to predict and confirm expectations (McCroskey \& Richmond, 1987), thereby increasing their perceived competence. This sets off a chain of behavior in which the student feels less anxious about communicating and thus more competent. Reduced anxiety and increased perceived competence means that the students should be more willing to communicate and should subsequently increase their frequency of $\mathrm{L} 2$ communication. In this way, the vicious cycle described earlier can be reversed, wherein increased frequency leads to improvement in language skills and a better perceived competence.

Although the expected differences between the immersion and nonimmersion programs were observed on communication variables, the results concerning reasons for studying French and attitudes toward French require further thought. The male immersion, the female immersion, and the female nonimmersion students showed similar attitudes toward French, but the male nonimmersion students showed somewhat lower attitude levels. Dörnyei (1990) noted that there is less commitment among foreign language learners to integrate with the target language culture. This may negatively influence the nonimmersion students' attitudes toward French. The finding that lower attitudes occurred only among the male nonimmersion group might be taken as support for the idea that males are less socially oriented than females (Bardwick, 1971; Gilligan, 1982; Maccoby \& Jacklin, 
1979). A similar pattern occurs in the students' reasons for studying French. The male nonimmersion students showed the lowest mean in three of the four orientations. Interestingly, the exception was the orientation toward meeting Francophones, where the female immersion students showed the lowest orientation and female nonimmersion students the highest. Given these results, however, it might be difficult to argue that females are generally more socially oriented.

The male immersion students showed the highest job-related orientation. The goal of getting a better job or earning more money may be what encouraged the males to enter the immersion program in the first place. It was the female nonimmersion students who showed the highest travel, knowledge, and personal-achievement orientations. It is possible that the increased experience of the immersion group gives them a more realistic view of the French language and the culture. The combined effects of a naive view of the language and its culture and the social orientation of females may be the reason the female nonimmersion students showed higher travel, knowledge, and personal-achievement orientations. It is interesting to note that the mean orientation of the males and the females only differed significantly in the nonimmersion group. The limited research concerning gender differences in second language acquisition makes it difficult to surmise why these findings occurred or if they could be replicated in another sample. Further research is necessary to go beyond these speculations.

The qualitative descriptions reveal that many of the students experienced anger after the negative experience, and that they actually felt even more determined to learn the language. Although one must be cautious in interpreting qualitative data, the responses might shed light on the underlying process, making this finding encouraging from an educational standpoint. The students suggested that, when faced with adversity, they attempted to rise to the occasion. They become even more motivated to learn the language in order to avoid similar negative situations in the future. This was especially true of the immersion students who indicated that the experience made them feel angry. The nonimmersion 
students had similar though less intense feelings. For instance, the nonimmersion students said they felt "unsure," "self-conscious," or "inadequate." The immersion students used words like "frantic" and "worried." The immersion students have much more time and energy invested in learning the second language than the nonimmersion students. This might explain the difference in emotional intensity of the two groups after a negative experience. Immersion students should be more accustomed to positive experiences, so they become habituated to those experiences. A negative experience, though, may be unexpected and, therefore, much more threatening. The opposite seems to be true for nonimmersion students. Perhaps paradoxically the nonimmersion students, who indicated more anxiety and a lower level of perceived competence in French, are less strongly affected by a negative experience. A positive experience is more novel to these students and, therefore, elicits stronger emotion. The immersion students said they felt "nice" or "fine" after a positive experience, but the nonimmersion students went further to say that they felt "wonderful," "elated," or "excited."

The results of the correlations among the communication variables in the immersion group versus the nonimmersion group also yielded some interesting findings. Research has consistently found that perceived competence and communication anxiety influence willingness to communicate (MacIntyre \& Clément, 1996) and accordingly the frequency of communication (MacIntyre $\&$ Charos, 1996). In the present study, perceived competence had little to no correlation in the immersion group, but for the nonimmersion students, perceived competence was a strong correlate of willingness to communicate and frequency of communication. These latter two variables were best predicted by anxiety among the immersion students.

There are several ways to explain these results. Speaking has been found to be the most anxiety-provoking form of communication (MacIntyre \& Gardner, 1991; McCroskey \& Richmond, 1987). It is often the case that in nonimmersion classrooms, it is usually the teacher who does most of the talking while the students take notes. The focus in these classrooms is not on authentic use of the 
L2 for communication (Harley, 1990). Because nonimmersion students tend to have less communicative competence than immersion students, perceived competence is a key factor affecting their level of willingness to communicate (Harley, 1990). This also helps to explain why perceived competence was so highly correlated with frequency of communication. If the students feel incompetent, they will be unwilling to communicate and also communicate less often.

Immersion students, on the other hand, are placed into many speaking situations. Once higher levels of linguistic competence have been achieved, students are expected to apply what they have learned. There would be much more pressure on the immersion students to speak well and meet performance standards, making anxiety a central factor for these students. A number of the students wrote that having francophone students in the class with them and a francophone teacher made them feel nervous and inadequate. It appears then that the students feel competent, but they are still anxious about communicating and proving themselves to others in the class. MacIntyre (1995), in discussing the effects of anxiety on performance, argued that anxiety may have little negative impact on simple tasks, but when demands increase, anxiety begins to have a negative effect. Performance is important to immersion students because they must communicate in French for the majority of their day. The greater communicative demand placed on immersion students and the emphasis on performance may leave the immersion students feeling a little more anxious about speaking (see Motley, 1991). MacIntyre and Charos (1996) found that perceived competence directly influenced frequency of communication in beginning students and wondered whether the same effect would be found among more experienced language learners. It appears that perceived competence might play a smaller role, and anxiety a greater role, among the advanced learners when it comes to frequency of communication and willingness to communicate. As McCroskey and Richmond (1987) suggested, knowing what to expect in communication situations might explain the results in both groups. Students with 
greater experience already see themselves as competent so they now must live up to certain social expectations, creating anxiety. For less experienced students, meeting social expectations takes a backseat to simply communicating coherently in the L2, making perceived competence the key factor.

\section{Conclusion}

The study found that substantial differences exist in the nonlinguistic outcomes between the immersion and the nonimmersion students. The immersion students reported lower L2 anxiety, higher L2 communication competence, greater willingness to communicate in the $\mathrm{L} 2$, and more frequent $\mathrm{L} 2$ communication. In the English-language situations, however, there were no significant differences between the two groups. There were gender differences in attitudes toward and reasons for studying French, but the overall pattern is somewhat inconsistent when one considers the orientation to meet the second language group. The qualitative results reveal that a negative experience in speaking French had mild detrimental effects on either group and might have actually enhanced motivation in some students. A negative experience, though, weighed more heavily on the immersion students, possibly because they expected better performance of themselves. Interestingly, both groups indicated negative experiences concerning speaking to Francophones in French and getting a reply in English. It is not clear why the Francophones spoke English to the students, but such occurrences could be prevented or at least lowered by having teachers prepare the community in advance that French-language students will be visiting. The teacher could help ensure that the L2 communication needs of the students are accommodated. Positive interactions with members of the L2 group might motivate the students to seek out further interactions in the future (Clément, Gardner, \& Smythe, 1977, 1980).

Finally, among the immersion students, anxiety was strongly correlated with willingness to communicate, but among the nonimmersion students, perceived competence was the key factor 
in predicting willingness to communicate. This suggests that the influences of the variables underlying WTC might change over time as students gain greater experience in the second language. Teachers in the nonimmersion program could increase the students' amount of mandatory L2 communication inside the classroom. This might eventually make the nonimmersion students more comfortable using the second language and possibly increase their perceptions of competence. Clearly, the nonlinguistic outcomes of immersion programs deserve further research attention and, we suggest, should be included routinely in program evaluation research.

Revised version accepted 29 November 1999

\section{References}

Bardwick, J. M. (1971). Psychology of women: A study of biocultural conflicts. New York: Harper \& Row.

Beatty, M. J. (1987). Communication apprehension as a determinant of avoidance, withdrawal, and performance anxiety. Communication Quarterly, 35, 202-217.

Borgatta, E. F., \& Bales, R. F. (1953). Interaction of individuals in reconstituted groups. Sociometry, 16, 302-320.

Bowd, A., McDougall, D., \& Yewchuk, C. (1994). Educational psychology for Canadian teachers. Toronto: Harcourt Brace \& Company.

Burgoon, J. K. (1976). The unwillingness-to-communicate scale:Development and validation. Communication Monographs, 43, 60-69.

Chapple, E. D., \& Arensberg, C. M. (1940). Measuring human relations: An introduction to the study of the interaction of individuals. Genetic Psychology Monographs, 22, 3-147.

Clément, R. (1980). Ethnicity, contact and communicative competence in a second language. In H. Giles, W. P. Robinson, \& P. Smith (Eds.), Language: Social psychological perspectives (pp. 147-154). Oxford: Pergamon Press.

Clément, R., Gardner, R. C., \& Smythe, P. C. (1977). Motivational variables in second language acquisition: A study of Francophones learning English. Canadian Journal of Behavioral Sciences, 9, 123-133.

Clément, R., Gardner, R. C., \& Smythe, P. C. (1980). Social and individual factors in second language acquisition. Canadian Journal of Behavioral Sciences, 12, 293-302. 
Clément, R., \& Kruidenier, B. G. (1983). Orientations on second language acquisition: 1 . The effects of ethnicity, milieu, and their target language on their emergence. Language Learning, 33, 273-291.

Dörnyei, Z. (1990). Conceptualising motivation in foreign-language learning. Language Learning, 40, 45-78.

Dörnyei, Z. (1998). Motivation in second and foreign language learning. Language Teaching, 31, 117-135.

Gardner, R. C. (1985). Social psychology and second language learning: The role of attitudes and motivation. London: Edward Arnold.

Gardner, R. C. (1996). Motivation and second language acquisition: Perspectives. Journal of the CAAL, 18, 19-42.

Gardner, R. C., \& Lambert, W. E. (1959). Motivational variables in second language acquisition. Canadian Journal of Psychology, 13, 266-272.

Gardner, R. C., \& Lambert, W. E. (1972). Attitudes and motivation in second language learning. Rowley, MA: Newbury House.

Gardner, R. C., \& MacIntyre, P. D. (1993). On measurement of affective variables in second language learning. Language Learning, 43, 157-194.

Gardner, R. C., Smythe, P. C., Clément, R., \& Gliksman, L. (1976). Second language acquisition: A social psychological perspective. Canadian Modern Language Review, 32, 198-213.

Gardner, R. C., Smythe, P. C., \& Lalonde, R. N. (1984). The nature and replicability of factors in second language acquisition (Research Bulletin no. 605). London: University of Western Ontario.

Gilligan, C. (1982). In a different voice: Psychological theory and women's development. Cambridge: Harvard University Press.

Goldman-Eisler, F. (1951). The measurement of time sequences in conversational behavior. British Journal of Psychology, 42, 355-362.

Harley, B. (1990). The development of second language proficiency. New York: Cambridge University Press.

Hines, S. C., \& Barraclough, R. A. (1995). Communicating in a foreign language: Its effects on perceived motivation, knowledge, and communication ability. Communication Research Reports, 12, 241-247.

Maccoby, E. E., \& Jacklin, C. (1979). The psychology of sex differences. Stanford, CA: Stanford University Press.

MacIntyre, P. D. (1994).Variables underlying willingness to communicate: A causal analysis. Communication Research Reports, 11, 135-142.

MacIntyre, P. D. (1995). On seeing the forest and the trees: A rejoinder to Sparks and Ganschow. Modern Language Journal, 79, 245-248.

MacIntyre, P. D., Babin, P. A., \& Clément, R. (1999). Willingness to communicate: Antecedents and consequences. Communication Quarterly, 47, 215-239. 
MacIntyre, P. D., \& Charos, C. (1996). Personality, attitudes, and affect as predictors of second language communication. Journal of Language and Social Psychology, 15, 3-26.

MacIntyre, P. D., \& Clément, R. (1996, August). A model of willingness to communicate in a second language: The concept, its antecedents and implications. Paper presented at the World Congress of Applied Linguistics (AILA), Jyväskylä, Finland.

MacIntyre, P. D., Clément, R., Dörnyei, Z., \& Noels, K. A. (1998). Conceptualizing willingness to communicate in a L2: A situational model of L2 confidence and affiliation. Modern Language Journal, 82, 545-562.

MacIntyre, P. D., \& Gardner, R. C. (1991). Methods and results in the study of anxiety in language learning: A review of the literature. Language Learning, 41, 85-117.

MacIntyre, P. D., Noels, K. A., \& Clément, R. (1997). Biases in self-ratings of second language proficiency: The role of language anxiety. Language Learning, 47(2), 265-287.

McCroskey, J. C. (1970). Measures of communication bound anxiety. Speech Monographs, 37, 269-277.

McCroskey, J. C. (1977). Oral communication apprehension: A summary of recent theory and research. Human Communication Research, 4, 78-96.

McCroskey, J. C. (1984). The communication apprehension perspective. In J. A. Daly \& J. C. McCroskey (Eds.), Avoiding communication: Shyness, reticence, and communication apprehension (pp. 13-38). Beverly Hills, CA: Sage.

McCroskey, J. C. (1992). Reliability and validity of the willingness to communicate scale. Communication Quarterly, 40, 16-25.

McCroskey, J. C., \& Baer, J. E. (1985, November). Willingness to communicate: The construct and its measurement. Paper presented at the annual convention of the Speech Communication Association, Denver, CO.

McCroskey, J. C., \& Daly, J. A. (1987). Personality and interpersonal communication. Newbury Park, CA: Sage.

McCroskey, J. C., \& McCroskey, L. L. (1986, May). Predictors of willingness to communicate: Implications for screening and remediation. Paper presented at the annual convention of the International Communication Association, Chicago.

McCroskey, J. C., \& Richmond, V. P. (1982). Communication apprehension and shyness: Conceptual and operational distinctions. Central States Speech Journal, 33, 458-468.

McCroskey, J. C., \& Richmond, V. P. (1987). Willingness to communicate. In J. C. McCroskey \& J. A. Daly (Eds.), Personal and interpersonal communication (pp. 129-156). Beverly Hills, CA: Sage. 
McCroskey, J. C., \& Richmond, V. P. (1990). Willingness to communicate: Differing cultural perspectives. Southern Communication Journal, 56, 72--77.

McCroskey, J. C., \& Richmond, V. P. (1991). Willingness to communicate: A cognitive perspective. In M. Booth-Butterfield (Ed.), Communication, cognition and anxiety (pp. 19-37). Newbury Park, CA: Sage.

McCroskey, J. C., Richmond, V. P., \& McCroskey, L. L. (1987). Correlates of self-perceived communication competence. Paper presented at the annual convention of the International Communication Association, Montreal, Canada.

Mortensen, D. C., Arnston, P. H., \& Lustig, M. (1977). The measurement of verbal predispositions: Scale development and application. Human Communication Research, 3, 146-158.

Motley, M. T. (1991). Public speaking anxiety qua performance anxiety: A revised model and an alternative therapy. In M. Booth-Butterfield (Ed.), Communication, cognition, and anxiety (pp. 85-104). Newbury Park, CA: Sage.

Oxford, R. (1996).Where are we regarding language learning motivation? Modern Language Journal, 78, 512-514.

Oxford, R., \& Shearin, J. (1994). Language learning motivation: Expanding the theoretical framework. Modern Language Journal, 78, 12-28.

Phillips, G. M. (1968). Reticence: Pathology of the normal speaker. Speech Monographs, 35, 39-49.

Phillips, G. M. (1977). Rhetoritherapy versus the medical model:Dealing with reticence. Communication Education, 26, 34-43.

Sellers, D. E., \& Stacks, D. W. (1991). Toward a hemispheric processing approach to communication competence. In M. Booth-Butterfield (Ed.), Communication, cognition and anxiety (pp. 45-59). Newbury Park, CA: Sage.

Tittle, C. K. (1986). Gender research and education. American Psychologist, 41, 1161-1168. 